\title{
Effects of Using the Seven E's Learning Cycle on the Technical Performance and Cognitive Achievement of Basic Basketball Skills
}

Dr/ Lamia Fawzy Mahrours ${ }^{1}$

Abstract:

The current research aims to use the Seven E's model and to identify its effects on the technical performance level of the following basic basketball skills (chest pass - rebound pass - dribbling - free throw - ladder shot) for female students of the second stage of basic education and the cognitive achievement level of the following (history - law - technical performance form) for female students of the second stage of basic education. The researcher used the experimental approach (two-group design) with pre- and postmeasurements. Research community included all second-grade female students of Al-Menshawy preparatory school for girls - Tanta during 2015-2016 academic year $(n=230)$. The researcher randomly chose (50) students $(21.7 \%$ of research community) as a main sample and divided them into two equivalent groups (experimental $=$ control $=$ 25). The experimental group used the Seven E's model while the control group used the regular (instruction and mode) method. Another (20) students from the same research community and outside the main sample were used a pilot sample. Results indicated that:

1. The educational program with Seven E's model had positive effects on the performance level of basketball skills under investigation of the experimental group with improvement percentages from $42.48 \%$ to $398.17 \%$ in favor of post-measurements.

2. The educational program with Seven E's model had positive effects on the cognitive achievement of the experimental group with improvement percentage of $328.99 \%$ in favor of post-measurements

3. The regular educational program with instruction and model had positive effects on the performance level of basketball skills under investigation of the control group with improvement percentages from $20.04 \%$ to $180.19 \%$ in favor of post-measurements.

${ }^{1}$ Assistant professor of Basketball - Department of Team and Racquet Sports Faculty of Physical Education - Tanta University.

Assiut Journal For Sport Science Arts 
4. The educational program with instruction and model had positive effects on the cognitive achievement of the control group with improvement percentage of $196.67 \%$ in favor of post-measurements 5. Post-measurements indicated statistically significant differences in favor of the experimental group on the performance level of basketball skills under investigation with improvement percentages ranging from $22.44 \%$ to $217.98 \%$.

6. Post-measurements indicated statistically significant differences in favor of the experimental group on the cognitive achievement with improvement percentage of $132.32 \%$.

7. The Seven E's model had positive effects on learning basketball skills and the cognitive achievement of students.

Key words: Constructivist Theory - Constructivist Learning Model Learning Cycle - Seven E's Learning Cycle

\section{Introduction and Research Problem:}

Education in Egypt is

now related to the future through transforming from negative to positive learning and from instructors to active facilitators. Governments are now play a vital role in leading, financing and monitoring the educational process as community became an active partner in it with all its sectors as beneficiaries of its outcomes. This is reflected on all components of the process (teachers - learners - curricula - methods of teaching ...) with the aim that the school becomes an enlightenment center for producing and acquiring experiences, capabilities, skills and potentials. Now, it is time for all workers in the educational field to stand together to provide Egypt with an authentic educational system that overcomes traditional instruction and concentrates on modern methods compatible with our modern age. This means to concentrate on new educational strategies with new methods of teaching to prepare a productive citizen and to provide this citizen with a sufficient space for innovative thinking (Abd Allah, M. 2016: 12,13).

Al-Hila, M. (2003) indicated that modern view of science means the integration of cognitive and behavioral aspects. This necessitates concentrating on these two aspects in addition to the learner and building his/her character cognitively, emotionally and technically so 
as to acquire experiences that modify his/her behavior. Zaitoun, H. \& Zaitoun, K. (2003) indicated that the traditional method of instruction and model doesn't allow sufficient space for exploration and innovation for the learner. In addition, the teacher should be more positive during the educational process (Al-Hila, M. 2003: 15) (Zaitoun, H. \& Zaitoun, K. 2003: 24).

Hasan, M. (2015) indicated that the educational process in general and tertiary education is a significant factor affecting the development requirements of the society. In addition, it is the main source of raising individuals with high mental abilities, technical efficacies and valuable behaviors that enable them to interact intelligently with current present facts and future changes (Hasan, M. 2015: 2).

Therefore, education should be learner-centered so that the learner can use previously acquired knowledge in learning new concept and to become a knowledge generator. But the real situation in teaching physical education in our schools indicates that the currently used method is instruction and model while neglecting other vital aspects, like thinking, that are vital experiences for raising an individual adaptive to all fields (Sadek, M. 2003: 145).

Since late 1980s, new trends appeared in teaching and learning. These trends resulted from the constructivist theory that generated several valuable teaching models. This theory appeared more than twenty years ago and dominated the educational thinking progressively. This led to applying new teaching ideas for skills. Several contemporary educators think that knowledge is built in the brain by the learner himself and this is the main root of the constructivist theory (Fawzy, A. 2014: 85).

With the beginning of the third millennium, reality necessitates that students should use modern learning approaches that integrate all psychological and social needs of students in addition to improving their desired behaviors inside the classroom. Educational psychologists and curricula experts indicated that modern approaches for learning are needed including the Seven E's constructivist model (Al-Deeb, M. 2004: 9).

Constructivist

philosophy is very recent and produced several new methods of teaching with several learning models. It concentrates on how to build up knowledge and how to 
acquire it. This theory is based on Piaget's Cognitive Constructivism and Vygotsky's Social Constructivism. Abd AlKareem, S. (2000) indicated that learning is limited to two views:

- Jean Piaget's view of learning where learning is identified by what learners get of scientific understanding outcomes

- Vygotsky's view of learning where learning is identified by the social context and requires a degree of professionalism in learning physical education (Abd AlKareem, S. 2000: 205).

The Seven E's model is a modern constructivist model that includes seven steps: Excitement: to stimulate learners - Exploration: to satisfy students' curiosity and cooperation for comprehending understandable meaning Explanation: to clarify concepts and define terms Expansion: to discover modern applications of the concept Extension: to clarify the relationships between a concept and other concepts Exchange: to mutually exchange ideas and experiences - Examinations: to evaluate students' learning and understanding (Eisenkraft 2003: 56-59).

Basic education schools are with significant effect on improving basic skills for students through physical education lesson if teachers follow modern methods with its effective role in improving the technical and cognitive performance of students.

Basketball is a team sport with a prominent place among other sports as it is the second popular game in Egypt and the Arab world only after soccer. It is among activities taught in physical education curricula with its basic skills being taught in physical education lessons. In addition, it is practiced as internal and external activities in colleges and is considered as an effective field suitable for students. Students can learn new skills with opportunities to practice what he/she learned according to his/her trends, abilities and desires (Fawzy, A. 2014: 12).

Basketball is rich in its individual and team skills (Fawzy, A. 2014: 3). It depends on basic skills for improving the technical performance level towards elite levels (Abd El-Daim \& Hassanain 1999: 44).

As a curriculum activity in the second stage of basic education, basketball includes the following skills: passing dribbling - shooting. These are the basic requirements for practicing basketball and all 
students should be at least good at these skills.

Basketball requires

scientific methods to achieve its goals. Using these methods makes it easy to understand and comprehend the skill in addition to analyzing and evaluating it. Basic basketball skills are the base for teaching basketball as learners get main headlines about the simplest learning processes of the correct technical performance in a life-long neural path.

As a supervisor of student-teachers' field training in second stage basic education schools, the researcher noticed that the dominant method is the traditional instruction and model without any active participation of students in the educational situation. This is not consistent with improvements of the educational system being initiated nowadays. In addition, students' numbers are increasing, and this adds more burden on teachers. Barakat, L. () indicated that regular methods of teaching should be changed if we want to fulfill the requirements of modern education and its purposes according to physical, psychological and motor growth stages of students and their increasing numbers (Ahmed L. : 165).
As other subjects, physical education should have its share of modern methods of teaching, especially when teaching basic basketball skills as teaching should be transferred from negative to positive participation of teachers and learners as well. In this case, the teacher's role is to facilitate learning through guidance and decrease of learning time. This increases the efficiency of learners.

Accordingly, the current research is trying to use the Seven E's model and to identify its role in clarifying motor performance stage for each basic basketball skill and its cognitive aspect. According to the researcher's knowledge, no previous study dealt with this issue. In addition, it is a try to identify the effects of modern methods of teaching on technical and cognitive aspects of learning.

\section{Aims:}

The current research aims to use the Seven E's model and to identify its effects on:

- The technical performance level of the following basic basketball skills (chest pass - rebound pass - dribbling - free throw ladder shot) for female students of the second stage of basic education. 
- The cognitive achievement level of the following (history - law technical performance form) for female students of the second stage of basic education.

\section{Hypotheses:}

1. There are statistically significant differences between the pre- and postmeasurements of the control group on the technical performance and cognitive achievement of basketball basic skills in favor of the postmeasurements.

2. There are statistically significant differences between the pre- and postmeasurements of the experimental group on the technical performance and cognitive achievement of basketball basic skills in favor of the post-measurements.

3. There are statistically significant differences between the post-measurements of the control and experimental groups on the technical performance and cognitive achievement of basketball basic skills in favor of the experimental group.

\section{Methods:}

Approach:

The researcher used the experimental approach (twogroup design) with pre- and post-measurements.

Participants:
Research community included all second-grade female students of AlMenshawy preparatory school for girls - Tanta during 20152016 academic year $(n=230)$. The researcher randomly chose (50) students $(21.7 \%$ of research community) as a main sample and divided them into two equivalent groups (experimental $=$ control $=25)$. The experimental group used the Seven E's model while the control group used the regular (instruction and mode) method. Another (20) students from the same research community and outside the main sample were used a pilot sample to verify the following:

- Validation of all tools and equipment used in this research

- Validity and reliability of tests and measurements

- Validation of the recommended program

The researcher excluded students from the main sample according to the following criteria:

- Members of the pilot sample

- Non-punctual students

- Students with medical permissions

Data normality for participants: The researcher performed the premeasurements to assure data normality of all participants on the controlling variables (age height - weight), mental 
abilities test (IQ), basketballspecific physical abilities, basketball technical performance and cognitive achievement test as seen in table (1).

\section{Table (1)}

Descriptive data of participants for data normality $(n=50)$

\section{\begin{tabular}{l|l|l|l|l|l|l|}
\hline \hline S & Variables & Measurement & Mean & Median SD & Kurtosis Squewness \\
\hline
\end{tabular}}

\begin{tabular}{|c|c|c|c|c|c|c|}
\hline \multicolumn{7}{|c|}{ 1- Growth Factors: } \\
\hline - Age & Year & IT.T. & $1 \pi .$. & $\cdot . V 1$ &.$\wedge \varepsilon_{-}$ & $.01-$ \\
\hline - Height & $\mathrm{Cm}$ & $10 V . V 7$ & $101 .$. & 1.89 & I.r.- & $\cdot Y \cdot-$ \\
\hline - Weight & $\mathrm{Kg}$ & $\sum \Lambda . \vee \uparrow$ & $\Sigma 9 . \cdots$ & 1.91 &.$\wedge \mu_{-}$ & $\because 0 \cdot-$ \\
\hline 2-IQ & Point & $0 \leqslant .91$ & $00 . .$. & $1 . V Y$ & .99 & $\cdot r_{-}$ \\
\hline \multicolumn{7}{|c|}{ 3- Physical Abilities: } \\
\hline \begin{tabular}{l|l|}
- & Arms power \\
\end{tabular} & $\mathrm{M}$ & r.IV & T.YO &. .79 & $.91-$ &.$r 4$ \\
\hline - Legs power & $\mathrm{Cm}$ & $1 \leq .1$. & $1 \leqslant . Y \mu$ & 1.11 & $\cdot \wedge \varepsilon_{-}$ & .17 \\
\hline - Speed & $\mathrm{Sec}$ & $1 \leqslant .94$ & $1 \leqslant . \leqslant 7$ & $1.9 \varepsilon$ & Yr.97 & ร.IV \\
\hline - Agility & $\mathrm{Sec}$ & Tr.VT & $r \leqslant . r_{0}$ & $Y .9$ & 11.80 & $Y . V \varepsilon_{-}$ \\
\hline - Accuracy & Point & $17 . \vee \wedge$ & $I V . .$. & $1.0 \leqslant$ & $.0 \Lambda_{-}$ & 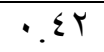 \\
\hline \multicolumn{7}{|c|}{ 4- Technical Variables: } \\
\hline - Chest pass & Number & $\varepsilon .0 \leqslant$ & $\varepsilon .$. & $1 . Y \cdot$ & $1 . \varepsilon_{-}$ & $\cdot r \leqslant$ \\
\hline - $\begin{array}{l}\text { Rebound } \\
\text { pass }\end{array}$ & Number & 7.94 & v... & $\cdot .99$ & $.70_{-}$ & $\cdot v \cdot$ \\
\hline - Dribbling & $\mathrm{Sec}$ & $\varepsilon \varepsilon . \vee 1$ & $\leqslant 0.47$ & $1 . V T$ & 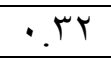 & $1 . T_{-}$ \\
\hline - Free throw & Point & r.v & $\varepsilon \ldots$ & $\cdot \Delta r$ & $\because \leqslant 0_{-}$ & $\because \mathrm{Vo}$ \\
\hline - Ladder shot & Point & $\varepsilon . \mu$. & $0 . \cdots$ & 1.17 & $1.7 \varepsilon$ & $\because 7_{-}$ \\
\hline 5- $\begin{array}{l}\text { Cognitive } \\
\text { achievement }\end{array}$ & Point & $\Lambda . \Gamma \varepsilon$ & 1.0 . & $1.0 Y$ & $1 . \pi_{-}$ & $\cdot r_{-}$ \\
\hline
\end{tabular}

Table (1) indicated that squewness values were between $( \pm 3)$. This directly indicates that data is normal and free radical distributions.

The researcher verified groups homogeneity on of all controlling variables (age - height - weight), mental abilities test (IQ), basketballspecific physical abilities, basketball technical performance and cognitive achievement test as seen in table (2). 
Table (2)

Homogeneity and difference significance between the premeasurements of both groups $(n 1=n 2=25)$

\begin{tabular}{|c|c|c|c|c|c|c|c|c|c|c|}
\hline \multirow{2}{*}{$S$} & \multirow{2}{*}{ Variables } & \multirow{2}{*}{ Measurement } & \multicolumn{2}{|c|}{ Experimental } & \multicolumn{2}{|c|}{ Control } & & \multirow{2}{*}{$\mathbf{F}$} & \multirow{2}{*}{$(\mathbf{t})$} & \multirow{2}{*}{$\mathbf{P}$} \\
\hline & & & Mean & SD士 & \multicolumn{2}{|c|}{ Mean $\mid \mathrm{SD} \pm$ differences } & & & & \\
\hline \multicolumn{11}{|c|}{ 1- Growth Factors: } \\
\hline & Age & Year & IT.YE & $\because V Y$ & (1) & $\because v \cdot$ & $\cdot .14$ & $1 . \cdot V$ & $\because 7$. & .00 \\
\hline & Height & $\mathrm{Cm}$ & $10 \% .7$. & I.VT & $10 V .94$ & $1 . \wedge \mathrm{V}$ & $\cdot{ }^{\prime}$ & 1.17 & .74 & $.0 T$ \\
\hline & Weight & $\mathrm{Kg}$ & $\leqslant \Lambda .07$ & r.IT & $\leqslant \wedge .97$ & $1 . v \cdot$ & $\cdot \varepsilon$ & $1.0 \mathrm{~V}$ & $\because V \leqslant$ & $\cdot . \leqslant V$ \\
\hline & IQ & Point & $0 \leqslant .97$ & 1.70 & $00 .$. & $1 . \wedge r$ & $\because \cdot \varepsilon$ & $1 . r^{\mu}$ & $\because \cdot 1$ & $\cdot .9 \varepsilon$ \\
\hline \multicolumn{11}{|c|}{ 3- Physical Abilities: } \\
\hline & Arms power & $\mathrm{M}$ & T. .9 & $\cdot . \vee 1$ & Y.Y & $\cdot .7 \mathrm{~N}$ &. .10 & 1.9 & $\because V V$ & $\cdot . \leqslant \varepsilon$ \\
\hline & Legs power & $\mathrm{Cm}$ & 15.17 & $1.1 \varepsilon$ & $1 \varepsilon . \varepsilon$ & $1.1 \cdot$ & $\cdot .14$ & $1 . v$ & $\because \varepsilon \cdot$ &. .79 \\
\hline - & Speed & $\mathrm{Sec}$ & $1 \leq . \leq 9$ & r... & $10 . r \Lambda$ & Y.o. & $\cdot .19$ & 1.07 & 1.70 & .11 \\
\hline - & Agility & $\mathrm{Sec}$ & rr.09 & $1 . Y V$ & rr.Ao & $1.0 Y$ & $\cdot r_{0}$ & $1 . \leqslant 1$ & $\because \Sigma Y$ & $\cdot .7 \mathrm{~V}$ \\
\hline & Accuracy & Point & $17 . V Y$ & 1.57 & $17 . \wedge \varepsilon$ & 1.70 &. .14 & $1 . Y \wedge$ &.$Y V$ & $\because \vee 9$ \\
\hline \multicolumn{11}{|c|}{ 4- Technical Variables: } \\
\hline & Chest pass & Number & 5.71 & $1 . Y_{0}$ & \&. & 1.10 & $\cdot r \Lambda$ & $1.1 \mathrm{~V}$ & $\because \wedge Y$ & $\cdot . \leqslant 1$ \\
\hline & $\begin{array}{l}\text { Rebound } \\
\text { pass }\end{array}$ & Number & 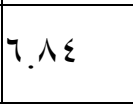 & $\cdot .99$ & $v .$. & $10^{\circ}$ &. .17 & $1 . \cdot 1$ & $\because \theta^{\circ}$ &. $.0 \mathrm{~V}$ \\
\hline & Dribbling & $\mathrm{Sec}$ & $\leqslant \leqslant . \wedge$. & 1.71 & $\varepsilon \varepsilon .7 Y$ & $1 . \wedge \wedge$ & .11 & T. &.$\mu^{\top}$ & $\cdot V Y$ \\
\hline & Free throw & Point & $r . \vee T$ & $\cdot . \wedge \wedge$ & Y.VY & $\because \vee 9$ & $\because \varepsilon$ & I. Tr & $\because .1 \mathrm{~V}$ & $\cdot . \wedge \mathrm{V}$ \\
\hline- & Ladder shot & Point & $\varepsilon . M$ & 1.19 & $\varepsilon . Y \varepsilon$ & 1.17 &. $.1 Y$ & $1 . \cdot \varepsilon$ & $\cdot r T$ & $\cdot V Y$ \\
\hline & $\begin{array}{l}\text { Cognitive } \\
\text { achievement }\end{array}$ & Point & $\Lambda, \Upsilon \Lambda$ & $1.0 \leqslant$ & A. $\varepsilon$. & 1.04 &. .14 & $1 . \cdot 1$ & $\because r$ & $\because \vee \wedge$ \\
\hline
\end{tabular}

$F$ table value on $P \leq 0.05$ and freedom degrees of $(24,24)=$ 1.98

(t) table value on $\mathbf{P} \leq \mathbf{0 . 0 5}=$ 2.06

Table (2) indicated that $F$ calculated values were lower than it table value. This directly indicates homogeneity of both groups on all research variables.

Data collection tools:

Growth Factors Tests:

- $\quad$ Age: date of birth (year)

- Height: with a

restameter $(\mathrm{cm})$

Weight: with medical

balance $(\mathrm{kg})$

Mental abilities test: 
The researcher used IQ test for old and young persons, prepared by Al-Ansary, S. (2008). This test measures IQ for individuals between 12 and 21 years. It contains (60) questions and several mental processes including completion of numeric chains, distinguishing shapes, understanding shapes, understanding words, identifying relations between letters chains or numbers chains and numeric deduction. The researcher chose this test for the following reasons:
- Easy to apply

- Suitable of the age group under investigation

- According to previous studies, it is highly valid and reliable (Soliman, L. 2004) (Nassar, M. 2010).

\section{Validity and Reliability of IQ} Test:

The researcher applied the IQ test to a pilot sample $(n=20)$ from the same research community and outside the main sample and compared upper and lower quartiles as seen in table (3).

Table (3)

means differences between upper and lower quartiles of IQ test for validity $(\mathbf{n}=\mathbf{2 0})$

\begin{tabular}{|c|c|c|c|c|c|c|c|c|}
\hline \multirow{2}{*}{\begin{tabular}{l|l} 
S & Test \\
\end{tabular}} & \multicolumn{2}{|c|}{$\begin{array}{c}\text { Upper } \\
\text { quartile }(n=5)\end{array}$} & \multicolumn{2}{|c|}{$\begin{array}{c}\text { Lower } \\
\text { quartile }(n=5)\end{array}$} & \multirow{2}{*}{$\begin{array}{c}\text { Means } \\
\text { differences }\end{array}$} & \multirow[t]{2}{*}{ (t) } & \multirow[t]{2}{*}{ ETA $^{2}$} & \multirow[t]{2}{*}{ Validity } \\
\hline & Mean & $\mathrm{SD} \pm$ & Mean & $\mathrm{SD} \pm$ & & & & \\
\hline \begin{tabular}{l|l}
1 & IQ
\end{tabular} & 07.7. & $\overline{I . Y 1}$ & $01 . \mu$. & $1 . \mu \varepsilon$ & $0 . r$. & 0.19 & $\cdot . \wedge 1$ & .9 . \\
\hline
\end{tabular}

(t) table value on $P \leq 0.05=2.30$

Effect size: 0: $0.30=$ weak $-0.30: 0.50=$ moderate $-\geq 0.05=$ strong

Table (3) indicated that the test is highly valid with strong effect size.

procedure with time interval of (7) days as the test was applied to a pilot sample $(n=20)$ from the same research community and outside the main sample as seen in table (4).

For reliability, the researcher used test/retest 
Table (4)

correlation coefficient between test and retest for IQ test reliability $(\mathbf{n}=\mathbf{2 0})$

\begin{tabular}{|c|c|c|c|c|c|c|}
\hline \multirow{2}{*}{$\mathbf{S}$} & \multirow{2}{*}{ Test } & \multicolumn{2}{|c|}{ Test } & \multicolumn{2}{|c|}{ Retest } & \multirow{2}{*}{$\mathrm{R}$} \\
\hline & & Mean & $\mathrm{SD} \pm$ & Mean & $\mathrm{SD} \pm$ & \\
\hline $\bar{~} 1$ & $\overline{\mathrm{IQ}}$ & 04.90 & $1.7 \varepsilon$ & $0 \leqslant . Y$. & 1.59 & .98 \\
\hline
\end{tabular}

$R$ table value on $P \leq 0.05=0.44$

Table (4) indicated high correlation coefficients between test and retest. This clearly shows that IQ test is highly reliable.

Basketball-specific physical tests:

According to review of literature $(13,5,15,20,22)$, the researcher chose the following tests:

- $\quad$ Legs power (wide jump from stance)

- Arms power $\quad(3 \mathrm{~kg}$ medicine ball throwing)

- Speed (30m running from flight)

\section{Table (5)}

means differences between upper and lower quartiles of physical tests for validity $(n=20)$

\begin{tabular}{|c|c|c|c|c|c|c|c|c|c|}
\hline \multirow[t]{2}{*}{$\mathbf{S}$} & \multirow{2}{*}{$\begin{array}{c}\text { Physical } \\
\text { variables }\end{array}$} & \multicolumn{2}{|c|}{\begin{tabular}{|c|}
$\begin{array}{c}\text { Upper quartile } \\
(n=5)\end{array}$ \\
\end{tabular}} & \multicolumn{2}{|c|}{$\begin{array}{c}\text { Lower } \\
\text { quartile }(n=5)\end{array}$} & \multirow{2}{*}{$\begin{array}{c}\text { Means } \\
\text { differences }\end{array}$} & \multirow[t]{2}{*}{$(\mathbf{t})$} & \multirow[t]{2}{*}{$\mathbf{E T A}^{2}$} & \multirow[t]{2}{*}{ Validity } \\
\hline & & Mean & $\mathrm{SD} \pm$ & Mean & $\mathrm{SD} \pm$ & & & & \\
\hline 1 & Arms power & T. & (I. & 1.10 & 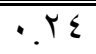 & 1.1. & 0.19 &.$\wedge 1$ & .9. \\
\hline 2 & $\begin{array}{l}\text { Legs } \\
\text { power }\end{array}$ & $10 . \mathrm{V}$. &.$V T$ & IT.E. & .09 & .r. & $V . r$ &.$\wedge 7$ & .94 \\
\hline 3 & Speed & ITEO & .77 & 17.10 &.$\wedge \varepsilon$ & r.7. & 7.19 & .10 & .94 \\
\hline 4 & Agility & YI.T. & $.9 r$ & YO.V. & $1 . \varepsilon$ & $\varepsilon . \varepsilon \cdot$ & $7 . \mu \mathrm{N}$ &.$\wedge \varepsilon$ & .91 \\
\hline 5 & Accuracy & 19.5. & 1.11 & 10.1. & $.9 \leq$ & $\varepsilon .1$. & 0.74 &.$\wedge$. &.$\wedge 9$ \\
\hline
\end{tabular}

(t) table value on $P \leq \mathbf{0 . 0 5}=\mathbf{2 . 3 0}$

Assiut Journal For Sport Science Arts 
Table (5) indicated that the tests is highly valid.

For reliability, the researcher used test/retest procedure with time interval of (7) days as the tests were applied to a pilot sample $(n=20)$ from the same research community and outside the main sample as seen in table (6).

\section{Table (6)}

correlation coefficient between test and retest for physical tests reliability $(\mathbf{n}=\mathbf{2 0})$

\begin{tabular}{|c|c|c|c|c|c|c|}
\hline \multirow{2}{*}{$S$} & \multirow{2}{*}{$\begin{array}{r}\text { Physical } \\
\text { variables }\end{array}$} & \multicolumn{2}{|c|}{ Test } & \multicolumn{2}{|c|}{ Retest } & \multirow{2}{*}{$\mathbf{R}$} \\
\hline & & Mean & SD \pm & Mean & SD \pm & \\
\hline & Arms power & I.^. & $\cdot . \varepsilon Y$ & 1.10 & 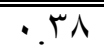 &. .94 \\
\hline & Legs power & $1 \leq .0$ & 1.9 & $1 \leqslant . Y_{0}$ & 1.41 &. .19 \\
\hline & Speed & 10.0 & $1 . r \mu$ & $10 .$. & $1 . r 4$ & .91 \\
\hline & Agility & rr.o. & $1 . \leqslant 7$ & Tr.E. & $1.0 \mathrm{~V}$ & .9 . \\
\hline & Accuracy & 18.10 & 1.00 & $1 V . \leqslant 0$ & $1 . r \mu$ &.$\wedge \wedge$ \\
\hline
\end{tabular}

$R$ table value on $P \leq 0.05=0.44$

Table (6) indicated high correlation coefficients between test and retest. This clearly shows that physical tests are highly reliable.

Technical Performance Tests:

According to review of literature $(13,5,15,27,2)$, the researcher chose the most

\section{Table (7)}

suitable tests for technical performance.

Validity and Reliability of technical performance tests:

For validity of tests, the researcher applied the tests to a pilot sample $(n=20)$ from the same research community and outside the main sample and compared upper and lower quartiles as seen in table (7).

means differences between upper and lower quartiles of technical performance tests for validity $(n=20)$

\begin{tabular}{|c|c|c|c|c|c|c|c|}
\hline \multirow{2}{*}{$\begin{array}{l}\text { Technical } \\
\text { variables }\end{array}$} & \multirow{2}{*}{\begin{tabular}{|c|}
$\begin{array}{c}\text { Upper quartile } \\
(\mathrm{n}=5)\end{array}$ \\
Mean|SD \pm \\
\end{tabular}} & \multicolumn{2}{|c|}{\begin{tabular}{c|} 
Lower \\
quartile $(n=5)$
\end{tabular}} & \multirow{2}{*}{$\begin{array}{c}\text { Means } \\
\text { differences }\end{array}$} & \multirow{2}{*}{$(\mathbf{t})$} & \multirow{2}{*}{ ETA $^{2}$} & \multirow{2}{*}{ Validity } \\
\hline & & Mean & SD \pm & & & & \\
\hline$\overline{\overline{\text { Ches }}}$ & IT.V.T.rV & 8.00 & $1 . Y \varepsilon$ & 1.10 & 7.1 & $\cdot \Delta r$ & .91 \\
\hline Rebound pass & 18.004 .11 & $v_{.} .$. & $1 . V Y$ & $1 . .00$ & 0.94 & $\cdot{ }^{\wedge}$ & .9 . \\
\hline Dribbling & r9.70 r. $\leqslant r$ & $\leqslant \leqslant .90$ & r.YT & $10 . \Gamma$. & V.0 & $\because \wedge \wedge$ & $.9 \varepsilon$ \\
\hline Free throw & $1 \cdot .0 \cdot 1 . V Y$ & r.^. & .97 & $7 . V$. & $7 . \wedge \varepsilon$ &.$\wedge 0$ & $.9 Y$ \\
\hline
\end{tabular}




\begin{tabular}{l|l|l|l|l|l|l|l|l}
\hline \hline Ladder shot & Ir.Vo \\
\hline
\end{tabular}

(t) table value on $P \leq 0.05=2.30$

Table (7) indicated that the tests are highly valid with strong effect size.

For reliability, the researcher used test/retest procedure with time interval of

\section{Table (8)}

(7) days as the tests were applied to a pilot sample $(n=20)$ from the same research community and outside the main sample as seen in table (8).

\section{correlation coefficient between test and retest for technical tests} reliability $(\mathbf{n}=\mathbf{2 0})$

\begin{tabular}{|c|c|c|c|c|c|}
\hline \multirow{2}{*}{\begin{tabular}{l|l}
$\mathrm{S}$ & $\begin{array}{l}\text { Technical } \\
\text { variables }\end{array}$ \\
\end{tabular}} & \multicolumn{2}{|c|}{ Test } & \multicolumn{2}{|c|}{ Retest } & \multirow{2}{*}{$\mathbf{R}$} \\
\hline & Mean & SD \pm & Mean & SD \pm & \\
\hline \begin{tabular}{l|l|l}
1 & Chest pass
\end{tabular} & A.7T & $\overline{r . r}$ & A.Vo & 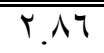 & $\cdot . \wedge 9$ \\
\hline 2 Rebound pass & IT.YA & $r . v q$ & ד.r. & $r . \varepsilon \varepsilon$ & $\cdot .9$. \\
\hline 3 Dribbling & rV.r. & 5.11 & $r v . \leqslant 0$ & $\varepsilon . \mu \nu$ & $\cdot \wedge \wedge$ \\
\hline 4 Free throw & 8.10 & r.r. & V.YO & 1.97 & $\cdot .94$ \\
\hline $\begin{array}{ll}\text { Ladder shot } \\
\end{array}$ & $9 .$. & $r .90$ & 9.0 & T.1T & $\cdot .9 Y$ \\
\hline
\end{tabular}

$R$ table value on $P \leq 0.05=0.44$

Table (7) indicated high correlation coefficients between test and retest. This clearly shows that technical tests are highly reliable.

The Cognitive Achievement Test (by the researcher):

This test aims to:

Identify students' acquisition of technical skills under investigation and knowledge related to the history, laws and skills of basketball.

Identify the preliminary and final behavior of students after

applying the Seven E's model and to formulate that in behavioral objectives.

\section{Preparation of Test:}

According to the aims of this test, the researcher reviewed related literature including (27) (3) (32) (2) and concluded that the material should include three main axes: history of the game - rules of the game - technical skills of the game.

The three axes were presented to a number of 
experts who are faculty members of sports psychology and basketball to identify their opinions about the axes. Relative importance of each axis is presented in table (9).

\section{Table (9)}

Relative importance of each axis of the test

\begin{tabular}{l|l|c}
\hline \hline $\mathbf{S}$ & \multicolumn{1}{|c|}{ Axis } & Relative importance \\
\hline \hline 1 & History of the game & $87 \%$ \\
\hline 2 & Rules of the game & $89 \%$ \\
\hline 3 & Skills of the game & $95 \%$ \\
\hline \hline
\end{tabular}

\section{Forming Items:}

According to protocols of writing items of tests and the related literature, the researcher formed (45) items and presented them to experts to identify their opinions about them. According to experts' opinions, only (39) items stayed in the test as items (9, $16,18,28,37,39)$ were eliminated.

Types of questions:

The researcher chose the multiple-choice type as students were asked to choose one response from three choices given. Questions should be suitable for students' level and should cover the three axes of the test. In addition, questions should be clear.
Preliminary version of the test:

The preliminary version included (45) items that cover the three axes of the tests

\section{Test instructions:}

Test instructions were written in a clear language and included how to record responses with sufficient space for required data.

\section{Validation of the preliminary} version:

Preliminary version was presented to experts of basketball, sports psychology and methods of teaching physical education from faculties of physical education. Experts' opinions indicated that only (39) items will remain as seen in table (10).

Table (10)

Preliminary and final count of items of the cognitive achievement test

\begin{tabular}{c|c|c|c|c|c|c|c}
\hline \hline S & Axis & $\begin{array}{c}\text { Preliminary } \\
\text { count }\end{array}$ & $\begin{array}{c}\text { Excluded } \\
\text { items } \\
\text { count }\end{array}$ & $\begin{array}{c}\text { Numbers of } \\
\text { excluded } \\
\text { items }\end{array}$ & $\begin{array}{c}\text { Modified } \\
\text { items } \\
\text { count }\end{array}$ & $\begin{array}{c}\text { Number } \\
\text { of } \\
\text { modified } \\
\text { items }\end{array}$ & $\begin{array}{c}\text { Final } \\
\text { count of } \\
\text { items }\end{array}$ \\
\hline 1 & History & $1 \cdot$ & 1 & 9 & - & - & 9 \\
\hline
\end{tabular}




\begin{tabular}{|c|c|c|c|c|c|c|c|}
\hline 2 & Rules & $1 T$ & $r$ & $1 \Lambda_{-17}$ & - & - & 11 \\
\hline 3 & Skills & rY & $r$ & $r q-r v-r \wedge$ & - & - & 19 \\
\hline & Sum & $\leqslant 0$ & 7 & 7 & - & - & rq \\
\hline
\end{tabular}

Table (10) indicated that

(6) items were excluded from (45) items leaving only (39) items in the tests.

Test Correction:

Each response takes only one mark according to the correction key prepared by the researcher.

Analysis of test items:

The test was applied to a pilot sample $(n=15)$ from the same research community and outside the main sample to verify difficulty and easiness coefficients for test according to the following equation:

Table (11)

Easiness, difficulty and distinction coefficients of the test

\begin{tabular}{|c|c|c|c|c|c|c|c|}
\hline & Easiness & Difficulty & Distinction & Item & Easiness & Difficulty & Disti \\
\hline 1 & .70 & . &. YYA & TY & ס & .70 &. YYA \\
\hline$r$ & ס & .70 &. YYA & Tr & .7 &.$\varepsilon$. & $\because Y \leq$. \\
\hline$\mu$ & .00 &.$\leqslant 0$ & $\cdot r \leqslant \Lambda$ & TE &.$\varepsilon$. & .7 . & $\because Y \varepsilon \cdot$ \\
\hline$\varepsilon$ &.$\varepsilon$ & .7 . & $. r \leq$. & ro & .70 & . To &. YYA \\
\hline 0 & $\because V \cdot$ &.$\mu$ & $\cdot Y ! \cdot$ & ry & .7 . & $\because \varepsilon$. & $\because Y \leq$. \\
\hline 7 &.$\leqslant 0$ & .00 & $. r \leqslant \Lambda$ & TV & ס ט & .70 & . YYA \\
\hline V & .00 &.$\leqslant 0$ & $. r \leqslant \Lambda$ & rᄉ &.$V \cdot$ &.$r$. & $\cdot Y$. \\
\hline$\Lambda$ & $\therefore \leqslant 0$ & .00 & $. r \leqslant \Lambda$ & rq &.$\varepsilon$. & .7 . & $. Y \leqslant$. \\
\hline 9 & .00 &.$\leqslant 0$ & $\cdot r \leqslant \Lambda$ & r. &.$\xi$. & .7 . & $\cdot r \leq$. \\
\hline 1. & .70 & ט &. YYA & T &.$\leqslant 0$ & .00 & $\cdot r \leqslant \Lambda$ \\
\hline
\end{tabular}

Easiness coefficient $=$ correct response / (correct response + wrong response)

Sum of easiness and difficulty coefficient $=1$. This means that easiness $=1-$ difficulty and vice versa.

Distinction coefficient is calculated through the following equation:

Distinction $=$ easiness $\mathrm{X}$ difficulty. Table (11) shows easiness, difficulty and distinction coefficients of the test. 


\begin{tabular}{|c|c|c|c|c|c|c|c|}
\hline 11 & . &.$V \cdot$ &.$Y I$. & Tr & .70 & . &. YY \\
\hline 14 & .7 . &.$\varepsilon$. &.$Y \varepsilon$. & rr & .00 &.$\leqslant 0$ & $. \quad Y \leqslant \wedge$ \\
\hline r &.$V \cdot$ & . r. & . & rs & .7. & . $\varepsilon$. &.$Y \varepsilon$. \\
\hline $1 \varepsilon$ &.$\varepsilon$. & .7. &.$Y \varepsilon$. & o &.$V$. & . &.$Y I$. \\
\hline
\end{tabular}

Follow Table (11)

Easiness, difficulty and distinction coefficients of the test

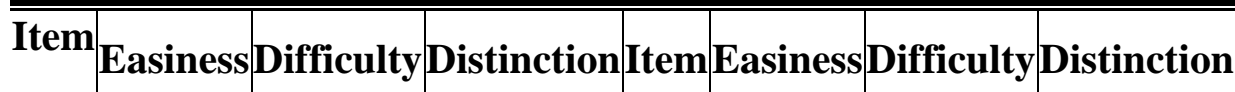

\begin{tabular}{|c|c|c|c|c|c|c|c|}
\hline 10 & $\because \leqslant 0$ & .00 & $. r \leqslant \Lambda$ & r & . $\varepsilon$ & .7 & $\because Y \varepsilon$. \\
\hline 17 & ס & .70 &.$Y K \wedge$ & TV & .00 & $\therefore \leqslant 0$ & $\cdot r \leqslant \Lambda$ \\
\hline 18 & $\because \varepsilon$ & .7 . & $. r \leqslant$. & $\Gamma \wedge$ & .7 . &.$\xi$. & 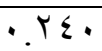 \\
\hline 11 & $\because \leqslant 0$ & .00 & $. r \leqslant \Lambda$ & rq & ס r. & .70 & . YrA \\
\hline 19 & .00 & $\because \leqslant 0$ & $. r \leqslant \Lambda$ & & & & \\
\hline$r$. & .7. & $\because \varepsilon$. & . $r \leq$. & & & & \\
\hline YI & $\because V \cdot$ & 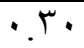 & 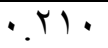 & & & & \\
\hline
\end{tabular}

Table (11) indicated that both easiness and difficulty coefficients ranged from $(0.3$ to 0.7) while distinction ranged from $(0.210$ to 0.250$)$. this means that the test has proper easiness, difficulty and distinction power.

Time of Test:

To calculate time of test, the researcher applied the following equation:

\section{Table (12)}

means differences between upper and lower quartiles of cognitive achievement test for validity $(n=20)$

\begin{tabular}{|c|c|c|c|c|c|c|c|}
\hline \multirow[t]{2}{*}{$\mathbf{S}$} & Test & $\begin{array}{c}\text { Upper } \\
\text { quartile } \\
(n=5)\end{array}$ & $\begin{array}{c}\text { Lower } \\
\text { quartile } \\
(n=5)\end{array}$ & \multirow[t]{2}{*}{$\begin{array}{c}\text { Means } \\
\text { differences }\end{array}$} & \multirow[t]{2}{*}{$(\mathbf{t})$} & \multirow[t]{2}{*}{ ETA $^{2}$} & \multirow[t]{2}{*}{ Validity } \\
\hline & & \multicolumn{2}{|c|}{$\operatorname{Mean} \mid \mathrm{SD} \pm$ Mean $\mid \mathrm{SD} \pm$} & & & & \\
\hline
\end{tabular}

Time of test $=$ (Time of first student + time of last student) / 2

Proper time for applying test was (45) minutes.

Validity and Reliability of test:

The researcher compared upper and lower quartiles for validity of the test as seen in table (12) 
\begin{tabular}{|l|l|l|l|l|l|l|l|l}
\hline $\begin{array}{l}\text { Cognitive } \\
\text { achievement }\end{array}$ & $1 \cdot .9 \cdot$ & $1 . r$ & $0.1 \cdot$ & $1 . \varepsilon \varepsilon$ & $0 . \wedge \cdot$ & v. ro & $\cdot . \wedge v$ & $\cdot . q r$ \\
\hline \hline
\end{tabular}

(t) table value on $\mathrm{P} \leq 0.05=2.30$

Table (12) indicated

statistically significant differences between upper and lower quartiles of the participants' responses on the cognitive achievement test. This indicates the validity of test.
For reliability, the researcher used test/retest procedure with time interval of (7) days as the test was applied to a pilot sample $(n=20)$ from the same research community and outside the main sample as seen in table (13).

Table (13)

correlation coefficient between test and retest for cognitive achievement test reliability $(n=20)$

\begin{tabular}{|c|c|c|c|c|c|c|}
\hline \multirow{2}{*}{$\mathbf{S}$} & \multirow{2}{*}{ Test } & \multicolumn{2}{|c|}{$\overline{\text { Test }}$} & \multicolumn{2}{|c|}{$\overline{\text { Retest }}$} & \multirow{2}{*}{$\mathbf{R}$} \\
\hline & & Mean & $\mathrm{SD} \pm$ & Mean & $\mathrm{SD} \pm$ & \\
\hline & achievement & $\overline{~ \Lambda . . .}$ & $1 . \varepsilon \wedge$ & A.ro & $1 . \mu$ & .99 \\
\hline
\end{tabular}

$R$ table value on $P \leq \mathbf{0 . 0 5}=0.44$

Table (13) indicated high correlation coefficients between test and retest. This clearly shows that the test is highly reliable.

The Seven E's Model:

The model includes seven stage that are considered as follows:

\section{Excitement stage:}

Aim: to stimulate students about a topic through questions.

Teacher's role:

- To stimulate students' curiosity and to support prediction

- To elicited responses and discover students' previous knowledge ar attitudes towards a concept or a topic

Students' role:

* To self-question about a topic or concept

* Why is this happening?

* What do I know about it?

- What can I know about the skill?

\section{Exploration Stage:}


Aim: to fulfill students' curiosity through cooperation to understand

Teacher's role:

* Facilitating and encouraging students' cooperation

* Assuring students' listening and note taking during exploration

- Helping students in activities

- Asking questions to direct students if necessary Students' role:

- Using exploration to fulfill curiosity

- Recording mutual discussion

- Making new predictions

- $\quad$ Thinking freely about the activity

- Taking notes and recording ideas

\section{Explanation Stage:}

Aim: to explain and clarify the concept and terms

Teacher's role:

- Providing students with correct definitions of terms and concepts

- Providing students with questions for explanation and verification

- Encoring students to clarify concepts and terms
- Explaining new definition through previous knowledge of students

Students' role:

- $\quad$ Explaining all possible answers and discussing others' explanations

- Cooperation for understanding teacher's explanations

- Group discussion and interaction with teacher for concluding definitions and explanations of concepts to be learned

\section{Expansion Stage:}

Aim: to discover new applications of the concept

Teacher's role:

- $\quad$ Encouraging students to apply and expand concepts and skill to new situations

- Asking students to clarify verifications through questions like: what do you already know? why do you think so?

Students' role:

- $\quad$ Providing realistic and reasonable conclusions

- Providing questions, answers, decisions and trials

- Applying learned terms, definitions, explanations and skills in new and similar situations 
- $\quad$ Taking notes and recording explanations

Extension Stage:

Aim: to identify the relation between a concept and other concepts as the concept extends beyond to subject to other subjects.

Teacher's role:

- Looking for connections between concepts

- Asking stimulating questions to help students see such relations

The

Recommended

Educational Program:

\section{General objectives:}

- Providing students of the second stage of basic education with concept and facts related to the history, rules and skills of basketball in addition to the technical content of skills (chest pass - rebound pass dribbling - free throw - ladder shot) using the Seven E's model.

- $\quad$ Providing students of the second stage of basic education with correct form of performing the following skills: chest pass - rebound pass - dribbling - free throw ladder shot.
Using Seven E's model, the researcher formulated the following objectives:

Cognitive behavioral objectives: by the end of this program students will be able to:

- Remember dates related to basketball

\section{basketball}

- Identify types of passes

- Understand technical performance of chest pass

- Understand technical performance of rebound pass

- Understand technical performance of dribbling

- Understand technical performance of free throw

- Understand technical performance of ladder shot

- Analyze technical performance of basketball according to its components

- $\quad$ Identify concepts related to basketball

\section{Skills behavioral objectives:} by the end of this program students will be able to:

- $\quad$ To perform chest pass

- To perform rebound pass

- $\quad$ To perform dribbling

- To perform free throw

- $\quad$ To perform ladder shot 
- $\quad$ To perform the skills in presence of more than one teammate correctly

- To perform basketball skills (chest pass - rebound pass - dribbling - free throw ladder shot) according to correct performance criteria

- $\quad$ Relate two or more skills correctly

Program principles:

- The program should be suitable students' characteristics and needs

- The program should consider logical organized thinking in presenting skills

- The program should consider individual differences

- $\quad$ Program contents should challenge students' abilities and stimulate their learning motivation

- The program should consider students' needs for activity

- The program should provide opportunities for all students to participate at once

- $\quad$ The program should help students to keep path towards learning

- $\quad$ The program should consider safety measures
- $\quad$ The program should provide enough tools, equipment and time

\section{Required capabilities:}

- Basketball court

- Basketballs

- Plastic cones

- Benches

- Measuring tapes

- Stop watch

- Medical balance

Measurements and tests:

- Growth factors data record

- IQ test

- $\quad$ Basketball-specific

physical abilities tests

- Basketball technical performance tests

- Cognitive achievement test

\section{Program content:}

- Historical evolution of basketball

- Rules of basketball

- Technical performance stages of basketball

- chest pass

- rebound pass

- dribbling

- free throw

- ladder shot

learning Pattern:

the researcher used the Seven E's model

\section{Assiut Journal For Sport Science Arts}


General framework:

The program included

(9) units distributed on (9) weeks (one lesson per week). Each lesson took (90) minutes. Total duration of the program was (9) weeks. Each unit is divided as follows:

- Administrative work (5 min)

- Warm-up (5 min)

- Physical preparation (15 min)

- Educational activity (60 min)

- Cool down (5 min)

Procedures:

The experimental group:

* Students head to the court and perform administrative work, warm up and physical preparation

- The main part is dealt with as follows:

- Excitement: Teacher askes questions to stimulate students

- Exploration: Students are divided into (4) groups (5 students per group) and provided with work sheets. Each group discusses the sheet. Teacher explains unclear things - Explanation: Teacher monitors students' progress and students explain their ideas to reach agreement. Students work in cooperation

- Expansion: Students apply the skills to be learned and teacher supervises performance

- $\quad$ Extension: Students link every two skills together. For example: dribbling - running shooting, to link dribbling with shooting.

- Exchange: students discuss with teacher about exercises for mastering the skill

- Examination: Teacher objectively evaluates students' performance.

The control group:

The control group used the regular (instruction and model) methods.

Pre-measurements:

Pre-measurement for both groups were taken from 110-2016 to 2-10-2016.

Main application:

The program was applied for (9) weeks from 310-2016 to 4-12-2016 (one lesson per week).

Post-measurements:

Post-measurements were taken from 5-12-2016 to 6-122016.

\section{Statistical treatment:}

The researcher used SPSS software to calculate the following: mean - SD - 
Squewness $\quad-$ correlation $\quad$ coefficient $-(\mathrm{t})$ test. 
Results:

Table (14)

Difference significance and improvement percentages between pre- and post-measurements of the control group on technical skills tests and cognitive achievement test $(n=25)$.

\begin{tabular}{|c|c|c|c|c|c|c|c|c|}
\hline \multirow{2}{*}{\begin{tabular}{l|l}
$\mathbf{S}$ & Variables
\end{tabular}} & \multicolumn{2}{|c|}{ Pre- } & Post- & Mea & \multirow{2}{*}{\begin{tabular}{|c|} 
Standard \\
error
\end{tabular}} & \multirow{2}{*}{$(\mathbf{t})$} & \multirow{2}{*}{\multicolumn{2}{|c|}{\begin{tabular}{l|c} 
& $\begin{array}{c}\text { Improvement } \\
\text { percentage } \\
(\%)\end{array}$ \\
\end{tabular}}} \\
\hline & Mean & $\mathrm{SD} \pm$ & $\operatorname{Mean} \mid S D \pm d$ & differences & & & & \\
\hline 1 Chest pass & $\varepsilon . \varepsilon$. & 1.10 & \begin{tabular}{|l|l|l|}
$\cdot . \Sigma$ & $1 . V Y$ \\
\end{tabular} & $0.7 \varepsilon$ & $.1 \mathrm{V9}$ & $\mid . V \varepsilon$ & $\because \cdots$ & $1 Y \Lambda .1 \Lambda$ \\
\hline 2 Rebound pass & $v_{.} .$. & $1 . \cdots$ & $|17.17| 1 . \varepsilon \cdot$ & 9.17 & .97 & $9.0 \leqslant$ & $\because \cdots$ & $1 \Gamma \cdot . \wedge T$ \\
\hline 3 Dribbling & $\sum \sum . T Y$ & $1 . \wedge \mathrm{N}$ & \begin{tabular}{|l|l|l|}
$0.7 \wedge$ & 1.90 \\
\end{tabular} & $1.9 \varepsilon$ & $\because V V$ & $11.0 \mathrm{~V}$ & $\because \cdots$ & $r \cdot . \varepsilon$ \\
\hline 4 Free throw & $T . V Y$ & $\because \mathrm{V9}$ & \begin{tabular}{|l|l|}
$9.7 \cdot$ & $1 . \mathrm{N}$ \\
\end{tabular} & 0.11 & $\cdot .77$ & $\Lambda .9 \varepsilon$ & $\therefore$ & 101.9 \\
\hline \begin{tabular}{|l|l} 
Ladder shot \\
\end{tabular} & $\varepsilon . Y \varepsilon$ & 1.17 & \begin{tabular}{|l|l|}
$11 . \wedge \wedge$ & $1.0 Y$ \\
\end{tabular} & $V . T \varepsilon$ &. $.7 \mathrm{~V}$ & $11 . \varepsilon \mathrm{V}$ & $\because \cdots$ & $11 . .19$ \\
\hline 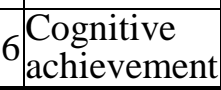 & A. $\varepsilon$. & 1.04 & $r \leq .9 Y \mid 1 . \wedge 1$ & $17.0 Y$ &.$\wedge \Lambda$ & $1 \mathrm{~L} . \mathrm{v}$ & $\cdots$ & $197.7 \mathrm{~V}$ \\
\hline
\end{tabular}

(t) table value on $P \leq 0.05=1.71$

Table (14) indicated statistically significant differences between pre- and post-measurements of the control group for technical performance level tests in favor of post-measurements as ( $\mathrm{t}$ ) calculated values ranged from 11.57 to 7.14 and improvement

percentages ranged from $180.19 \%$ to $20.04 \%$. in addition, there are statistically significant between the preand post-measurements of the control group on cognitive achievement test in favor of post-measurement.

\section{Table (15)}

\section{Difference significance and improvement percentages between} pre- and post-measurements of the experimental group on technical skills tests and cognitive achievement test $(n=25)$.

\begin{tabular}{|c|c|c|c|c|c|c|c|c|}
\hline $\mathbf{S}$ & Variables & $\frac{\text { Pre- }}{2}$ & $\begin{array}{c}\text { Post- } \\
\text { Mean|SD } \pm\end{array}$ & $\begin{array}{c}\text { Means } \\
\text { differences }\end{array}$ & $\begin{array}{c}\text { Standard } \\
\text { error }\end{array}$ & $(\mathbf{t})$ & $\mathbf{P}$ & $\begin{array}{c}\begin{array}{c}\text { Improvement } \\
\text { percentage } \\
(\%)\end{array} \\
\end{array}$ \\
\hline & Che & $\varepsilon .71 \quad 1.50$ & \begin{tabular}{|l|l|}
$1 V .9 Y$ & $1 . \wedge 1$ \\
\end{tabular} & Tร & .74 & $Y 1 . \cdot T$ & $\because \cdots$ & rAr.91 \\
\hline & Rebou & $7 . \wedge \varepsilon \cdot .99$ & Yr.7.1.VT & 17.27 &. .11 & rr.ov & $\cdots$ & $r \leqslant 0 . \cdot r$ \\
\hline & Dribbling & $\varepsilon \varepsilon . \wedge \cdot(1.7)$ & Yo.VV I. As & 19.4 &.$V \varepsilon$ & ro.v9 & $\because \cdots$ & $\sum Y . \leqslant \Lambda$ \\
\hline & Free throw & $r . \vee \tau \cdot . \wedge \wedge$ & $17 . Y .1 .1 \varepsilon$ & TY. $\varepsilon \varepsilon$ & .77 & $11 . \wedge$. & $\because \cdots$ & Tr. \\
\hline & Ladder shot & $\begin{array}{lll}.1 .19 & 1.19 \\
\end{array}$ & YI.VY I. . & IV.ru & $.7 \varepsilon$ & r..9Y & $\because \cdots$ & rqA. IV \\
\hline & $\begin{array}{l}\text { Cognitive } \\
\text { achievement }\end{array}$ & $\Lambda . r \wedge \mid 1.0 \leqslant$ & ro.0r|1.9r| & YV.YE & . & .87 & & rY^.99 \\
\hline
\end{tabular}

(t) table value on $\mathrm{P} \leq 0.05=1.71$ 
Table (15) indicated statistically significant differences between pre- and post-measurements of the experimental group for technical performance level tests in favor of postmeasurements as $(\mathrm{t})$ calculated values ranged from 26.92 to
18.80 and improvement percentages ranged from $398.17 \%$ to $41.48 \%$. in addition, there are statistically significant between the preand post-measurements of the experimental group on cognitive achievement test in favor of post-measurement.

Table (16)

Difference significance and improvement percentages between post-measurements of the control and experimental groups on technical skills tests and cognitive achievement test $(n 1=n 2=25)$

\begin{tabular}{|c|c|c|c|c|c|c|c|}
\hline \multirow{2}{*}{ S Variables } & \multicolumn{3}{|c|}{\begin{tabular}{|l|l|} 
Experimental & Control \\
\end{tabular}} & \multirow{2}{*}{$\begin{array}{c}\text { Means } \\
\text { differences }\end{array}$} & \multirow{2}{*}{$\begin{array}{c}\text { Standard } \\
\text { error }\end{array}$} & \multirow{2}{*}{$(\mathrm{t})$} & \multirow{2}{*}{$\mathbf{P}$} \\
\hline & Mean & SD \pm & Mean $\mathbf{S D} \pm \mathbf{c}$ & & & & \\
\hline 1 Che: & IV.9Y & $1 . \wedge 1$ & $|l \cdot . \varepsilon| 1 . V T$ & $\overline{\nabla . \wedge \wedge}$ & $10 . \leqslant Y$ & $\because \cdot$ & $10 \leqslant . V Y$ \\
\hline 2 Rebound pass & YT.T. & 1.17 & $17.17 / .2 \cdot$ & $V . \varepsilon \varepsilon$ & $17.1 \mathrm{~V}$ & $\because$ & $11 \varepsilon .1 \mathrm{~V}$ \\
\hline 3 Dribbling & YO.VV & $1 . \wedge \varepsilon$ & ro.71 1.90 & 9.91 & $11 . \cdot Y$ & $\because$ & Yr. $\varepsilon \varepsilon$ \\
\hline 4 Free throw & 17.4. & $1.1 \varepsilon$ & $9.7 \cdot 1 . \mathrm{MN}$ & 7.7. & IV.AM & $\because$ & IVY.Vq \\
\hline 5 Ladder shot & 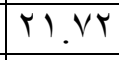 & 1.79 & $11 . \wedge 11.04$ & $9 . \wedge \varepsilon$ & $r \cdot .9 r$ & $\because \cdot$ & $r \backslash \vee .91$ \\
\hline $6 \begin{array}{l}\text { Cognitive } \\
\text { achievement }\end{array}$ & ro.0r & 1.94 & $r \leqslant .9 Y \mid, .11$ & 1.7. & 19.74 & & \\
\hline
\end{tabular}

(t) table value on $\mathbf{P} \leq \mathbf{0 . 0 5}=\mathbf{1 . 6 8}$

Table (16) indicated statistically significant differences between postmeasurements of the experimental and control groups for technical performance level tests in favor of the experimental group as $(\mathrm{t})$ calculated values ranged from 15.42 to 20.93 and improvement percentages ranged from $22.44 \%$ to
$217.98 \%$. in addition, there are statistically significant between the post-measurements of the experimental and control groups on cognitive achievement test in favor of experimental group.

\section{Discussion:}

Table (14) indicated statistically significant differences between the preand post-measurements of the 
control group on technical performance tests and cognitive achievement test in favor of post-measurements.

The researcher thinks that improvements in the control group resulted from the positive role of teacher in the regular method as she provides verbal instructions describing the skill and how to perform it in addition to the model of performance. Also, continuous evaluation and feedback during and after the activity provide students with opportunities to learn basic basketball skills.

In addition, improvements of the cognitive achievement of basic basketball skills (chest pass rebound pass - dribbling - free throw - ladder shot) resulted from information provided by the teacher during regular teaching as teachers provided useful information about history, rules and skills of basketball.

The researcher thinks that the regular (instruction and model) method provided students with information about the history, rules and correct performance of basic basketball skills. This helps them to form a correct image about how to perform the skill. Therefore, this method positively affected the performance level and cognitive achievement of the control group.

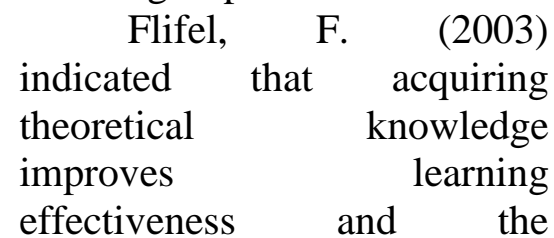
performance level of a skill depends on teacher's ability to provide learners with sufficient knowledge so that they learn and acquire the skill quickly (Flifel, F. 2003: 3).

These results are consistent with results of Mohamed, T. (2008), AlMaghawry, M. (2009) and Abd El-Latif, M. (2014) who indicated that instruction and model methods had positive effects on the technical performance and cognitive achievement of sports skills.

This proves the first hypothesis stating that "There are statistically significant differences between the preand post-measurements of the control group on technical performance and cognitive 
achievement tests in favor of the post-measurements".

Table (15) indicated statistically significant differences between the preand post-measurements of the experimental group on technical performance and cognitive achievement tests in favor of the postmeasurements.

The researcher thinks that these improvements are due to the use of the Seven E's model that excites students' curiosity and provide them with opportunities of exploration, expansion, extension in addition to real opportunities for them to practice the learned skills. And providing them with evaluative feedback about their performance. This is consistent with Zaitoun, H. \& Zaitoun, K. (2002) who indicated that the Seven E's model improves students' learning (Zaitoun, H. \& Zaitoun, K. 2002: 224).

This is consistent with previous results of Cavallo Appleton (2001), Kaleli et al (2010), Rashed, M. (2014), Abu Raia, M. (2015) and Abd Allah, M. (2016).
The researcher thinks that using Seven E's model with the experimental group encouraged students to think scientifically and improved their self-guidance skills in addition to excite their curiosity and positive thinking of the skills to be learned. It created a positive learning atmosphere and provided students with opportunities to conclude knowledge. These factors attract students' attention to lessons and improved their expectations. Mussa, M. (2003) and Ahmed, W. (2009) indicated that the Seven E's model improves knowledge acquisition of learners.

Zaitoun, A. (2007) indicated that the Seven E's model provides learners with opportunities to think and acquire knowledge and this helps them to find the best solution for problems they face (Zaitoun, A. 2007: 58).

The researcher thinks that students of the experimental group managed to think positively and effectively and this is reflected on their cognitive achievement in basketball. The Seven E's 
model helped students to form knowledge through exchanging their thoughts and ideas in addition to cooperative work and group discussions. This helps them to remember knowledge acquired and leads them to active learning. Mahmoud, I. (2003) indicated that problem-based learning leads to mastering quality learning as knowledge and information acquired by students remain active in their minds to be used later. $\mathrm{He}$ added that it is the quality not the quantity of information that matters if they are important and fulfill basic learning needs (Mahmoud, I. 2003: 230).

This is consistent with Abd Allah, A. *2004), Nabeeh, H. (2005) and Al-Maghawry, M (2009) who indicated that constructivist learning strategies play a major role in cognitive achievement of learners and this indicates its vital role in learning sports activities.

This proves the second hypothesis stating that "There are statistically significant differences between the preand post-measurements of the experimental group on technical performance and cognitive achievement tests in favor of the postmeasurements".

Table (16) indicated statistically significant differences between the postmeasurements of the experimental and control groups on technical performance and cognitive achievement tests in favor of the experimental group. This indicates that the Seven E's model was more effective in improving students' learning compared to regular (instruction and model) method as it helped them to achieve learning behavioral objectives and considered their needs and attitudes. It also provided them with a positive role during learning.

The researcher thinks that the Seven E's model helped students of the experimental group to learn and master the skills under investigation through dividing the skill into small parts in the light of kinematic chain of the skill and relate these parts to relevant information in a nonlinear way. Abu Harga et al (2001) indicated that teaching 
strategies lead to increasing learning effect and acquiring new skills by learners who maintain them in their minds for later use.

The researcher thinks the Seven E's model attracted the students' attention and made the learning process more attractive to them because of stimulating their thinking positively. It also helped them to discuss and communicate their ideas and this improved their desire for learning as it organized their thoughts to reach solutions for questions imposed in the work sheet. This is reflected on their technical performance level of basic basketball skills. Zaghloul, M. \& Al-Saieh, M. (2004) indicated that learning is affected by the methods used by teachers. This means that the effect of experimentationbased learning is transferred faster than traditional learning.

In addition, the Seven E's model had positive effects on the cognitive achievement of the experimental group, compared to the control group. This means it was more effective than the regular method. The researcher thinks that the cognitive content included items about history, rules and skills o0f basketball and related these items in an easy-to-understand way.

Abd Allah, M. (2016) indicated that the Seven E's model helped work groups to exchange ideas and thoughts to understand the questions and cooperate in solving them. It provided them with confidence and freedom of thinking in addition to freely discussing their ideas with the teacher. This supported cooperative work among students. In addition, competition among students deepened their understanding of the concluded solutions. It improved their thinking skills and made them at the center of the educational proves. This model helps students to become free in bearing the responsibility of improving their communication skills and positively helped them to acquire knowledge. AlTantawy, E. (2003) indicated that under constructivist learning, learners are more active in digging the correct solutions for problems they 
face (Abd Allah, M. 2016: 23) (Al-Tantawy, E. 2003: 58).

The researcher thinks that the Seven E's model increased the cognitive achievement of students as they acquired information and knowledge that helped them to remember the relevant topics and to achieve educational goals.

This is consistent with Mussa, M. (2003), AlKhodary, N. (2009) and Helmy, W. (2009) who indicated that the Seven E's model improves several aspects of learners including thinking, finding solutions and finding errors. In addition, it helped students to organize their thoughts and improved their critical, deduction and analytical skills (Mussa, M. 2003: 182) (Al-Khodary, N. 2009: 125) (Helmy, W. 2009: 95).

This is also consistent with Mostafa, O. (2006) and Mostafa, T. (2008) who indicated the effectiveness of constructivist learning in improving learners' interaction and challenge to find solutions for the problems they face.
The researcher thinks that improvements witnessed in the experimental group resulted from using the Seven E's model that improved their technical performance and cognitive achievement. These improvements are because of cooperation and competition among students to reach solutions. The Seven E's model achieved both social and educational bases of learning. Hussain, M. (2005) indicated that cognitive and social development of individuals is improved more positively in cooperative contexts as students accepted each other and helped each other (Hussain, M. 2005: 75).

This is consistent with results of Rashed, M. (2014), Abd El-Latif, M. (2014), Hasan, M. (2015) and Abd Allah, M. (2016).

This the third hypothesis stating that "There are statistically significant differences between the postmeasurements of the experimental and control groups on technical performance and cognitive achievement tests in favor of the experimental group". 


\section{5}

\section{Conclusions:}

8. The educational program with Seven E's model had positive effects on the performance level of basketball skills under investigation of the experimental group with improvement percentages from $42.48 \%$ to $398.17 \%$ in favor of post-measurements.

9. The educational program with Seven E's model had positive effects on the cognitive achievement of the experimental group with improvement percentage of $328.99 \%$ in favor of postmeasurements

10. The regular educational program with instruction and model had positive effects on the performance level of basketball skills under investigation of the control group with improvement percentages from $20.04 \%$ to $180.19 \%$ in favor of postmeasurements.

11. The educational program with instruction and model had positive effects on the cognitive achievement of the control group with improvement percentage of $196.67 \%$ in favor of postmeasurements
12. Post-measurements

indicated statistically significant differences in favor of the experimental group on the performance level of basketball skills under investigation with improvement percentages ranging from $22.44 \%$ to $217.98 \%$.

\section{Post-measurements} indicated statistically significant differences in favor of the experimental group on the cognitive achievement with improvement percentage of $132.32 \%$.

14. The Seven E's model had positive effects on learning basketball skills and the cognitive achievement of students.

\section{Recommendations:}

- Using the Seven E's model in teaching basic sports skills for various sports, especially basketball.

- Using the Seven E's model in teaching basic sports skills in physical education lessons of pre-tertiary education.

- Using the Seven E's model by teachers and coaches as an effective means for 
teaching sports skills in general and especially basketball skills.

\section{References:}

1- Abd Allah, Mohamed S. (2016): Effects of Seven E's model on learning some basic soccer skills for students of the second stage of basic education. Master dissertation Faculty of Physical Education - Tanta University (in Arabic)

\section{2- Abd El-Daim, M. \&} Hasanain, M. (1999): Modern trends in basketball: practical and theoretical principles (learningcoachingmeasurement- selectionrules). Dar Al-Fikr Al-Araby Cairo - Egypt (in Arabic).

3- Abd El-Kader, Amr A. (2004): Design of a recommended educational program with constructivist learning model and its effects on learning some basketball attack skills. Doctoral dissertation - Faculty of Physical Education for Men Helwan University (in Arabic)

4- Abd El-Latif, Montaser M. (2014): Effects of using computer-based constructivist model on learning some basic handball skills. Doctoral dissertation - faculty of
Physical Education - Al- Minia

University (in Arabic)

\section{5- Abu Harga, M.; Zaghloul,} M. \& Abd El-Monem, $\mathbf{H}$. (2001): Problems of school physical education curricula: diagnosis and treatment. Markz Al-Ketab Press - Cairo - Egypt (in Arabic).

6- Ahmed, Lotfy B. Studies on Developing the Arab World. Dar Al-Merrikh - Riyadh KSA

7- Ahmed, Wafa H. (2009): effectiveness of using Seven E's model for teaching science on modifying alternative scientific concepts and improving some critical thinking skills of $1^{\text {st }}$ grade preparatory students. Master dissertation- faculty of Education - Al- Minia University (in Arabic)

8- Al-Deeb, Mohamed M. (2004): Studies in cooperative learning. Alam Al-Kotob Cairo - Egypt (in Arabic)

9- Al-Fenikh, Lamia S. (2000): Dependence and independence on cognitive fierld and its relationship with some personality variables of female students of faculty of education at Al-Kaseem. Master dissertation - Faculty of 
Education for Women at AlKaseem- Buraida - KSA (in Arabic)

10- Al-Gendy, Omina A. (2003): Effects of using Whitely model on improving cognitive achievement and procedural skills and scientific thinking of $5^{\text {th }}$ grade pupils. Journal of Scientific Education - Egyptian Society of Scientific Education, Vol.6, no.1, Faculty of Education Ain Shams University (in Arabic)

11- Al-Heela, Mohamed M. (2003): Methods and strategies of teaching. Dar Al-Ketab AlGamey - Cairo - Egypt - in Arabic).

\section{2- Al-Khodary, Nada} (2009): Effects of using a Seven E's computerized program on improving higher thinking skills of technology among students of $7^{\text {th }}$ grade of basic education in Gaza. Master dissertation - Islamic University - Gaza - Palestine (in Arabic)

13- Allawy, M. \& Radwan, M. (1994): Motor Performance Tests. Dar Al-Fikr Al-Araby Cairo - Egypt (in Arabic).

14- Al-Maghawry, Mohamed A. (2009): A constructivist learning model and its effects on learning some basic volleyball skills for students of the second stage of basic education. Master dissertation Faculty of Physical Education - Al-Minia University (in Arabic)

15- Al-Tantawy, Effat $M$. (2002): Methods of teaching and learning and its application in educational research. The Anglo-Egyptian Library Cairo - Egypt (in Arabic).

16- Al-Tantawy, Effat $M$. (2015): Modern trends in teaching sciences. Markaz AlKetab Press - Cairo - Egypt (in Arabic).

17- Appleton , $\mathrm{K}$ (2001) . Analysis and description of student learning since chasses using constructive based model , Journal of research in science teaching, vol34.

18- Eisenkraft (2003) . Expanding the 5E Model ," The science teacher", vol .70, no.6 journal for high school science educators published by the national science teachers association .

19- Fawzy, A. \& Salama, A. (2004): Basketball for juniors. The Egyptian Library - 
Alexandria - Egypt (in Arabic).

20- Fawzy, Ahmed A. (2014):

Basketball: history - principles - basic skills. Alam Al-Riada and Dar Al-Wafa Press Alexandria 0 Egypt (in Arabic).

21- Flefil, Fatma M. (2003): Effects of using the figure $7 \mathrm{~s}$ on the cognitive achievement and technical performance of some basic basketball skills of students of the second stage of basic education. Journal of Sports Sciences. Faculty of Physical education - Al-Minia University (in Arabic)

22- Hasan, Fatma A. (2005): Effects and educational program based on individual multi-media on learning some basic basketball skills for female students of faculty of physical education - teaching branch. Doctoral dissertation Faculty of Physical Education - Tanta University (in Arabic)

23- Hasan, Maged S. (2005): Effects of Cooperative and programmed learning methods on the effectiveness of performing some basic boxing skills for female beginners. Master dissertation - Faculty of
Physical Education - Mansoura University (in Arabic)

24- Hasan, Mahmoud A. (2015): Effects of using constructivist learning model on improving the performance level of some basic soccer skills for pupils of the first stage of basic education. Master dissertation - Faculty of Physical Education - Tanta University (in Arabic)

\section{5- Hasan, Mahmoud A.} (2015): Effects of using constructivist learning model on improving the performance level of some basic soccer skills for pupils of the first stage of basic education. Master dissertation - Faculty of Physical Education - Tanta University (in Arabic)

26- Hasan, Omnia M. (2005): Effectiveness of cooperative learning approach on learning some basic basketball skills for students of faculty of physical education. Master dissertation Faculty of Physical Education for Women - Alexandria University (in Arabic)

27- Hasanain, Mohamed S. (1994): Measurement and Evaluation in Physical Education, part I, $3^{\text {rd }}$ ED. Dar 
Al-Fikr Al-Araby - Cairo Egypt.

28- Kaleli , G.Y of Ertem , E of Cepnis (2010): The effect of the material based on the $7 \mathrm{E}$ model on the fourth grade students conpre hension skill about fraction concepts, the faculty of Education, Artvin coruh, University, Artvin turkey.

29- Mahmoud, Ibrahim W. (2003): Learning: principles theories and application - Dar Al-Marifa - Cairo - Egypt (in Arabic).

30- Mathew S , D . K (1987) . Measurement physical education phi Iedelohia.

31- Mohamady, Ala El-Din (2002): Effects of an educational program with animation on learning some basic basketball skills for pupils of the first stage of basic education. Master dissertation Faculty of Physical Education - Al-Minia University (in Arabic)

32- Mohamed, Taher M. (2008): Effects of using constructivist learning model on the performance level of some track and field events for students of faculty of physical education - Al-Minia
University. Master dissertation

- Faculty of Physical Education

- Al-Minia University (in Arabic)

33- Nabeeh, Hussam El-Din (2005): Effects of constructivist learning approach on the cognitive and emotional levels and the performance level of handball. Doctoral dissertation - Faculty of Physical Education for Men - Helwan University (in Arabic)

34- Nassar, Mostafa S. (2010): Design of an educational program with brain storming and its effects on acquiring basic teaching skills for student-teachers of teaching branch - Faculty of Physical Education - Tanta University. Master dissertation - Faculty of Physical Education - Tanta University (in Arabic).

35- Othman, Othman M. (2006): Comparing the effectiveness of a constructivist learning model and the integrated approach on some technical and cognitive variables.

36- Rashed, Mohamed F. (2014): Design of an educational program with Seven E's model and its effects 
on concepts and dimensions of movement in some basic volleyball skills for students of the preparatory schools. Master dissertation - Faculty of Physical Education - South Valley University (in Arabic) 37- Sadek, Muneer M. (2003): Effectiveness of Seven E's model in teaching science and improving cognitive achievement and some procedural skills of students of $2^{\text {nd }}$ grade preparatory school. Journal of Scientific Education, no. 3, Faculty of Education Ain Shams University (in Arabic)

38- Zaghloul, M. \& Al-Saiah, M. (2004): Technology of preparing and qualifying physical education teachers, $2^{\text {nd }}$ ED. Dar Al-Wafa - Alexandria - Egypt (in Arabic)
39- Zaitoun, Aiesh (2007):

Constructivist theory and strategies of teaching science. Dar Al-Shurouk - Cairo Egypt (in Arabic)

40- Zaitoun, H. \& Zaitoun, K. (2003): learning and teaching: a constructivist perspective. Alam Al-Kotob Cairo - Egypt (in Arabic).

\section{1- Zghloul, Melody} Mohamed Saad (2015): Effects of using Whitley constructivist model on some hockey basic skills for students of faculty of physical education. Master dissertation - Faculty of Physical Education - Tanta University (in Arabic).

42- Zidan, Mostafa M. (1999): Basketball for teacher and coach. Dar Al-Fikr AlAraby - Cairo - Egypt (in Arabic). 